\title{
Desulfurization of gasoline using novel mesoporous carbon adsorbents
}

\author{
Mansoor Anbia $\cdot$ Sajedeh Karami
}

Received: 17 July 2014/ Accepted: 6 December 2014/Published online: 17 December 2014

(C) The Author(s) 2014. This article is published with open access at Springerlink.com

\begin{abstract}
Ordered mesoporous carbon (OMC) adsorbents have been prepared using spherical SBA-16 mesoporous silica, as a template. The synthesized materials were studied by X-ray diffraction, scanning electron microscopy and nitrogen adsorption-desorption isotherms. OMCs have been tested for adsorption of dibenzothiophene (DBT) as model sulfur compound from gasoline fuels. The OMC showed higher sulfur adsorption due to large mesopore volume and high specific surface area. The results confirm the significance of the adsorbent pore size and its surface chemistry for the adsorption of DBT from petroleum fuels. Langmuir and Freundlich isotherm models were used to fit equilibrium data for OMC. The equilibrium results were best demonstrated by the Langmuir isotherm.
\end{abstract}

Keywords Mesoporous SBA-16 - OMC - Adsorption · Gasoline fuels · Dibenzothiophene

\section{Introduction}

Removal of organosulfur compounds from liquid hydrocarbon fuels has become the most important responsibility of current petroleum refineries [1,2]. Sulfur compounds are the main obstruction in reducing the air pollution without

\section{Anbia ( $\square)$}

Research Laboratory of Nanoporous Materials, Faculty of Chemistry, Iran University of Science and Technology, Tehran 16846-13114, Iran

e-mail: anbia@iust.ac.ir

\section{S. Karami}

Research Laboratory of Advanced Materials, Chemistry and Chemical Engineering Research Center of Iran, P.O. Box 14335-186, Tehran, Iran their removal from fuels [3]. Approximately, all sulfurcontaining hydrocarbons in liquid fuels are changed to sulfur-free compounds and $\mathrm{H}_{2} \mathrm{~S}$ by catalytic hydrodesulfurization (HDS) reactions during the fuel processing. However, the HDS process is the best-known technology for desulfurization of liquid fuels. It cannot professionally remove thiophenic compounds (TC) including dibenzothiophene (DBT), 4,6-dimethyldibenzothiophene (4,6DMDBT), and benzothiophene (BT) [4-8]. Therefore, in deep HDS, the conversion of these increasingly more resistant key substituted dibenzothiophenes largely causes the required operating conditions for the production of ultra-low sulfur fuels. Intensive attempts are being made in development in the direction of designing, preparing, testing and up-scaling, effective, practical and strong deep and ultra-deep desulfurization systems, such as desulfurization catalysts and sorbents [9]. Not only catalytic HDS but also selective adsorption is often considered for the deep and ultra-deep removal of the HDS-resistant S-containing compounds from liquid fuels. Nanoscience and nanotechnology have gained considerable importance due to the needs and applications of nanomaterials in almost all areas of human endeavor. Nanomaterials are suitable candidates to fulfill requirements of high sensitivity and selectivity in solid-liquid phase extraction and removal of organosulfur compounds from liquid hydrocarbon fuels [10]. The major advantage of adsorptive desulfurization is the chemical selectivity of adsorption, in contrast to the non-selective catalytic hydrogenation used in the HDS process [11].

Several types of adsorbent have been reported, including various types of zeolites and metal loaded zeolites, such as MCM-22 zeolite, cation exchanged Y-zeolites, heteroatom zeolites and ion-exchange zeolites of $\mathrm{Cu}(\mathrm{I})$ and $\mathrm{Ag}(\mathrm{I})$-beta [12-15]. Ordered mesoporous carbons (OMCs), among 
different adsorbents, such as CMK-1, CMK-3 and CMK-5 are favorable materials for adsorption of several compounds due to their unique properties, for example, high pore structure of ordered mesoporous, high thermal stability, narrow pore size distribution, large specific surface area, as well as excellent chemical and physical stabilities have attracted much attention [16]. Recently, highly selective ligand-immobilized mesoporous materials have been received great attention due to high adsorption capacity, and fast kinetic performances, and reusability for several cycles use. The mesoporous materials can be modified into nano-engineered adsorbents by functionalization of ligands for effective separation and removal of organosulfur compounds [17]. Both non-functionalized and functionalized ordered mesoporous carbons have been used for desulfurization applications, such as the mesoporous carbon, CMK-5, prepared using hexagonal Al-SBA-15 mesoporous silica template, and have been used for adsorption of DBT from petroleum fuels [18]. The mesoporous carbons supply a layer of abundant hydroxyl groups as the binding sites for immobilization of $\mathrm{O}$ - and $\mathrm{N}$-donor ligands. Moreover, the straight channel material will facilitate for the entering and diffusion of DBT according to open active sites of the $\mathrm{O}$ - and $\mathrm{N}$-donor atoms of the immobilized ligand [19].

In the present study, OMC has been synthesized using SBA-16, as silica templates because of tailored porosity, high specific surface area, high stability and convenience of functionalization of the aforementioned mesostructures. We have various carbon precursors, such as furfuryl alcohol, sucrose and ethylene gas. We have used furfuryl alcohol as carbon precursors. OMC after carbonization formed hard carbon framework in the 3-D mesoporous network of the silica template. The structural order of the carbon frameworks was kept in same possession after silica template dissolution with $\mathrm{NaOH}$ or $\mathrm{HF}[20,21]$. The structural order and textural properties of the adsorbents have been characterized by powder X-ray diffraction (XRD), $\mathrm{N}_{2}$ adsorption-desorption isotherms (BrunauerEmmett-Teller, BET technique), and scanning electron microscopy (SEM).

\section{Experimental}

\section{Materials}

Hydrochloric acid $(\mathrm{HCl})$, sulfuric acid $\left(\mathrm{H}_{2} \mathrm{SO}_{4}\right)$, sodium hydroxide $(\mathrm{NaOH})$, aluminum chloride $\left(\mathrm{AlCl}_{3}\right)$, oxalic acid (OA), sucrose, 1,3,5-trimethylbenzene (TMB), tetraethyl orthosilicate, dibenzothiophene (DBT), ethanol, furfuryl alcohol (FA), $n$-hexane and the toluene OMC were from E. Merck (Germany). The copolymer poly ethylene oxide)- poly (propylene oxide)-poly (ethylene oxide) surfactant (Pluronic $\mathrm{P}_{123}, \quad \mathrm{MW}=5,800$ ), and Pluronic F127 (EO106PO70EO106, Sigma) as a structure-directing agent or soft template were from Aldrich. Double-distilled deionized water was used for preparation of solutions.

Instruments

XRD spectra were recorded by XRD diffractometer (Philips 1830) equipped with a liquid nitrogen-cooled germanium solid-state detector using $\mathrm{Cu}-\mathrm{K}_{\alpha}$ radiation over a range of $1^{\circ}<2 \theta<10^{\circ}$. The specific surface area was estimated by Nitrogen adsorption-desorption using the Brunauer-Emmett-Teller (BET) method. Scanning electron microscopy (SEM) images of adsorbents were observed using a Philips XL30 instrument after gold coating to increase their conductivity. A UV-Vis spectrophotometer (Perkin Elmer model Lambda 25) was used for determining the amount of DBT adsorbed by the adsorbents.

\section{Synthesis of SBA-16}

Two poly(alkylene oxide)-type triblock copolymers, Pluronic $\mathrm{F}_{127}\left(\mathrm{EO}_{106} \mathrm{PO}_{70} \mathrm{EO}_{106}\right.$, Sigma $)$ and $\mathrm{P}_{123}\left(\mathrm{EO}_{20}\right.$ $\mathrm{PO}_{70} \mathrm{EO}_{20}, \mathrm{EO}=$ ethylene oxide, $\mathrm{PO}=$ propylene oxide, $\mathrm{MW}=5,800$, Aldrich), were dissolved together in aqueous $\mathrm{HCl}$ solution at $313 \mathrm{~K}$ with stirring for $5 \mathrm{~h}$. Tetraethyl orthosilicate was added to the solution at $308 \mathrm{~K}$, and magnetic stirring was continued for $15 \mathrm{~min}$ at the same temperature. The molar composition of the mixture was as follows: $\quad \mathrm{P} 123 / \mathrm{F} 127 / \mathrm{TEOS} / \mathrm{HCl} / \mathrm{H}_{2} \mathrm{O}=1 / 2.3 / 621 / 2,727 /$ 89,182 . This mixture was kept under static conditions in an oven for $24 \mathrm{~h}$ at the same temperature. Subsequently, the mixture was placed in an oven at $373 \mathrm{~K}$ for hydrothermal treatment for $24 \mathrm{~h}$. A white precipitate was recovered by filtration and dried without washing at $373 \mathrm{~K}$ overnight. After that, the surfactant was removed by calcination at $823 \mathrm{~K}$ increasing the temperature to $823 \mathrm{~K}$ with a heating of $1{ }^{\circ} \mathrm{C} / \mathrm{min}[22]$.

\section{Synthesis of $O M C$}

The OMC was prepared using AlSBA-16, which in turn was synthesized by adding an ethanolic solution of $\mathrm{AlCl}_{3}$ $(0.113 \mathrm{~g}$ in $50 \mathrm{~mL}$ ethanol) to $1.0 \mathrm{~g}$ of SBA-16 (to afford $\mathrm{Si} / \mathrm{Al}$ mole ratio of 20) and ultrasonicating for $1 \mathrm{~h}$. Then, the ethanol solvent was completely evaporated in a rotary evaporator and the sample was calcined at $823 \mathrm{~K}$ in air for $4 \mathrm{~h}$ [23]. For preparation of OMC, FA was dissolved in TMB in a 40/60 volume ratio and OA was added to this solution (FA:TMB:OA mole ratio of 200:185:1) containing $0.535 \mathrm{ml} \mathrm{g}^{-1}$ furfuryl alcohol. The resulting solution was 
filtrated in the pores of AlSBA-16. After complete mixing, the mixture was placed into the oven at $308 \mathrm{~K}$ for $1 \mathrm{~h}$ and then at $373 \mathrm{~K}$ for $1 \mathrm{~h}$. The resulting sample was further heated for $2 \mathrm{~h}$ at $623 \mathrm{~K}$. After the sample was cooled at the room temperature, $0.268 \mathrm{~mL}$ furfuryl alcohol was added. This sample was again heated at 373 and $623 \mathrm{~K}$. The final heating (carbonization) was done at $1,173 \mathrm{~K}$ with the heating rate of $3.7 \mathrm{~K} \mathrm{~min}^{-1}$. All heating treatments were performed under self-generated gas atmosphere using a quartz reactor equipped with a porous plug.

DBT adsorption studies

A DBT solution $\left(1,000 \mathrm{mg} \mathrm{kg}^{-1}\right)$ in $n$-hexane was used for adsorption studies. The optimum procedure for adsorption of DBT onto OMC included adding $20 \mathrm{mg}$ of the adsorbent (OMC) into $10 \mathrm{~mL}$ of $1,000 \mathrm{mg} \mathrm{kg}^{-1} \mathrm{DBT}$ in $n$-hexane and stirring at $298 \mathrm{~K}$ for $60 \mathrm{~min}$. Then, the adsorbent was separated from the solution by a filter paper and the solution was subjected to UV-Vis measurement. The measurements were performed using the UV-Vis spectrophotometer in the range of $190-500 \mathrm{~nm}$. The amount adsorbed $\left(q_{\mathrm{e}}\right)$ was calculated from the following equation [24].

$q_{\mathrm{e}}=\left(C_{0}-C_{\mathrm{e}}\right) V / m$

where $C_{0}$ and $C_{\mathrm{e}}$ are the initial and equilibrium concentrations of DBT in the bulk phase, respectively, $V$ is the volume of the liquid phase and $m$ is the amount of adsorbent. The amounts of DBT adsorbed onto the adsorbents at any time $\left(q_{t}\right)$ were obtained from the following equation:

$q_{t}=\left(C_{0}-C_{t}\right) V / m$

where $C_{t}$ is the bulk concentration of DBT at any time $t$.

\section{Results and discussion}

Materials' characterization

The structure of the OMC was studied using low angle XRD. The ending XRD model for OMC, achieved in the $2 \theta$ range of $0^{\circ}-10^{\circ}$, is presented in Fig. 1 in cooperation with SBA-16 for contrast. The mesoporous silica SBA-16 and OMC displays three well-determined peaks indexed as (110), (200) and (211), characteristics of the bodycentered 3D cubic space group I $\mathrm{m} 3 \mathrm{~m}[25,26]$. The angles of diffraction of OMC were still in focus, and the intensity was nearly the same as that of SBA-16. This indicates that OMC synthesized by direct method still has high-order three-dimension cubic structure as that of SBA-16. The XRD pattern of the material is almost similar to that of SBA-16 which indicates that the OMC is

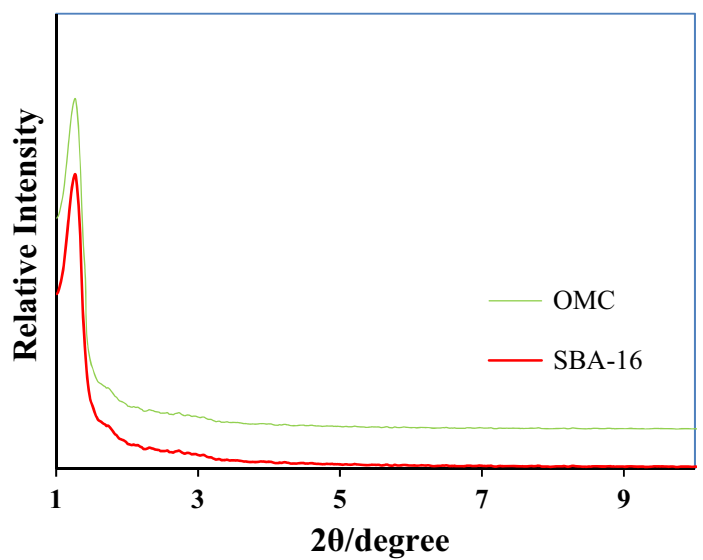

Fig. 1 Powder X-ray diffraction patterns of SBA-16 and OMC

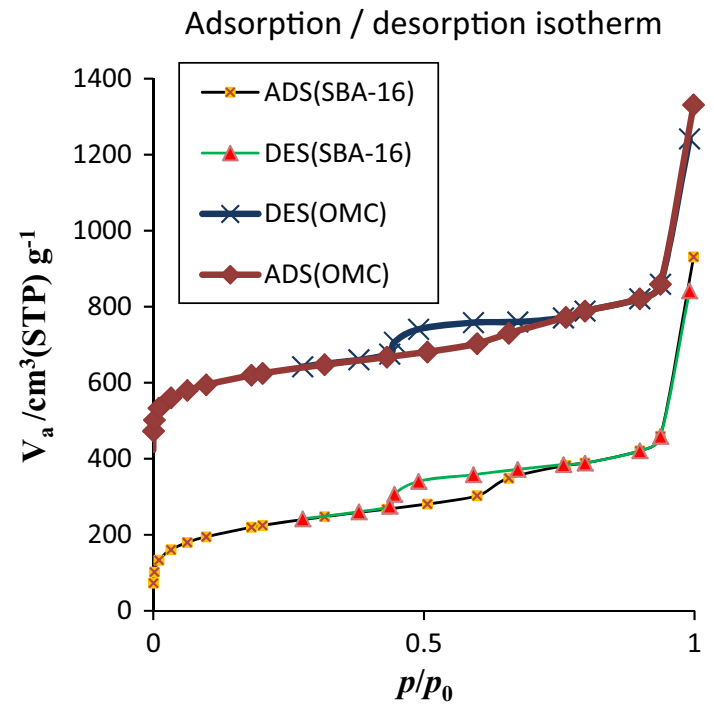

Fig. $2 \mathrm{~N}_{2}$ adsorption-desorption isotherms of SBA-16, and OMC at $77 \mathrm{~K}$

a true replica of the large-pore mesoporous silica SBA16. Figure 2 shows the adsorption/desorption isotherms of nitrogen at $77 \mathrm{~K}$ on SBA-16, and OMC. All isotherms exhibit a type IV profile according to the BET classification. Each isotherm shows a distinct hysteresis loop, which is a characteristic of mesoporous adsorbents [27]. The properties of mesoporous sorbents are recorded in Table 1. The specific surface area of OMC is $1,206.9 \mathrm{~m}^{2} \mathrm{~g}^{-1}$, which is higher than the specific surface area of SBA-16 $\left(806.18 \mathrm{~m}^{2} \mathrm{~g}^{-1}\right)$. On the other hand, the specific pore volume of OMC is $1.722 \mathrm{~cm}^{3} \mathrm{~g}^{-1}$, which is higher than SBA-16 $\left(1.1588 \mathrm{~cm}^{3} \mathrm{~g}^{-1}\right)$ [28]. The SEM image (Fig. 3) of carbon shows the presence of wellordered domains of $3 \mathrm{D}$ cubic mesostructure and is the best demonstration on the synthesis of well-ordered Im3m-type mesostructured carbon [29]. 
Table 1 Structural property of samples determined by nitrogen adsorption

\begin{tabular}{llcl}
\hline Adsorbent & d spacing $(\mathrm{nm})$ & $A_{\text {BET }}\left(\mathrm{m}^{2} \mathrm{~g}^{-1}\right)$ & $V_{p}\left(\mathrm{~cm}^{3} \mathrm{~g}^{-1}\right)$ \\
\hline SBA-16 & 2.71 & 806.18 & 1.1588 \\
OMC & 2.01 & $1,206.9$ & 1.722 \\
\hline
\end{tabular}

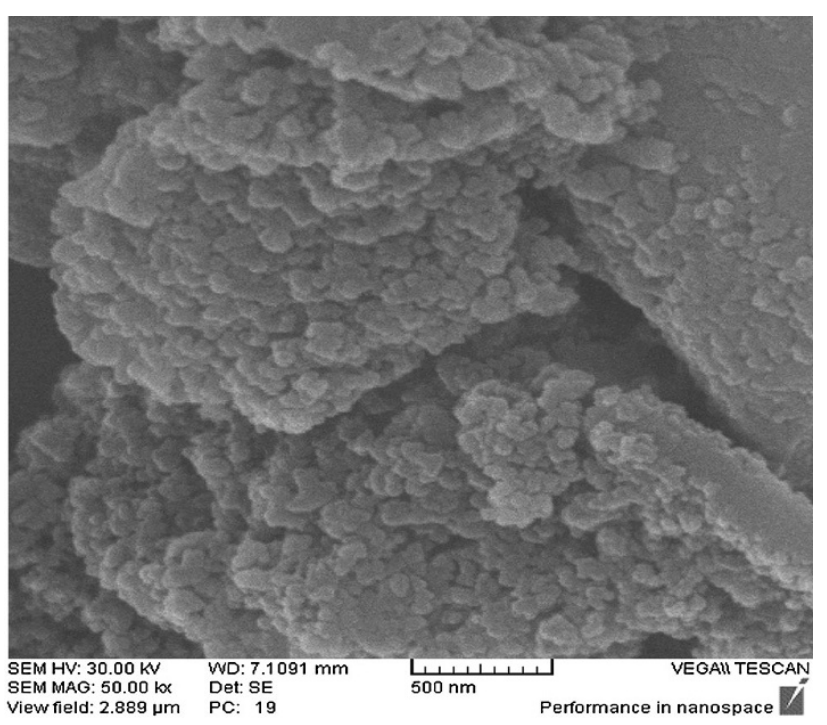

Fig. 3 SEM image of sample (OMC)

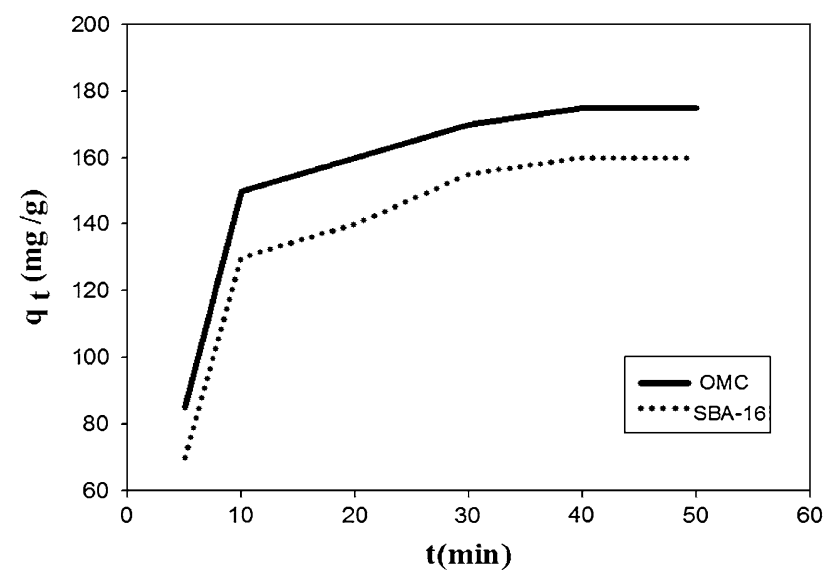

Fig. 4 Comparison of adsorption desulfurization by SBA-16 and OMC (DBT: $1,000 \mathrm{mg} / \mathrm{L}$, adsorbent dosage: $20 \mathrm{mg} / \mathrm{L}$, temperature: $25{ }^{\circ} \mathrm{C}$, stirring time: $360 \mathrm{~min}$

\section{Adsorption studies}

\section{Comparison of desulfurization on OMC, SBA-16}

To measure the adsorption capacities, the adsorption isotherm studies were performed at equilibrium conditions. The adsorption isotherms of DBT on the adsorbents are shown in Fig. 4. These results indicate that the extent of
Table 2 Comparative data of the adsorption capacity of OMC and SBA-16 with those of adsorbents used

\begin{tabular}{lcl}
\hline Sorbent & $\begin{array}{l}\text { Optimized adsorption } \\
\text { capacity }\left(\mathrm{mg} \mathrm{g}^{-1}\right)\end{array}$ & References \\
\hline MCM-41 & 0.80 & {$[32]$} \\
Ag-MCM-41 & 25.40 & {$[32]$} \\
MSN & 4.60 & {$[32]$} \\
Ag-MSN & 32.6 & {$[32]$} \\
SBA-16 & 29.56 & This study \\
OMC & 50.32 & This study \\
\hline
\end{tabular}

DBT adsorption was much higher on OMC samples than on the SBA-16. The time required for adsorption equilibrium is around $40 \mathrm{~min}$. The adsorption rate was related to the content of the active adsorption sites on the matrix of the adsorbent. The outcome shows that different mesoporous materials have meaningful different sulfur adsorption capacities that depend not only on the textural structure but also on the surface functional groups. The OMC exhibits high adsorption capacity than SBA-16, which is due to its larger BET surface area and bigger mesoporous volume.

On the other side, the OMCs demonstrate faster adsorption rate than SBA-16 which is due to the bigger mesoporous volume. It has been recommended that the adsorption process would occur in a series of diffusion steps into the mesopores and then into the micropores. It takes longer time to reach equilibrium when the sample has a small mesoporous volume. According to these results, OMC was chosen as the suitable adsorbent for the adsorption of DBT in this study. The saturated adsorption capacity of different samples is calculated by integral calculus from breakthrough curves and listed in Table 2 [30].

\section{Effect of initial concentration}

The experiment with $0.02 \mathrm{~g}$ OMC in $10 \mathrm{ml}$ solution (Fig. 5) shows the effect of stirring time and initial concentration on the sorption of DBT by OMC. The plots show that the adsorption of DBT increases with increase in the stirring time and reaches equilibrium earlier for solutions with lower initial concentrations. The adsorption curves are slightly increased and is continuous until it reaches saturation. The results make it clear that the DBT adsorption was fast in the initial stages of the interaction period, and afterwards it becomes slow near the equilibrium. This phenomenon was due to the fact that a large number of unfilled surface sites were available for adsorption during the initial stage, and after a period of time, the outstanding unfilled surface sites were difficult to be involved due to repulsive forces between the solute 


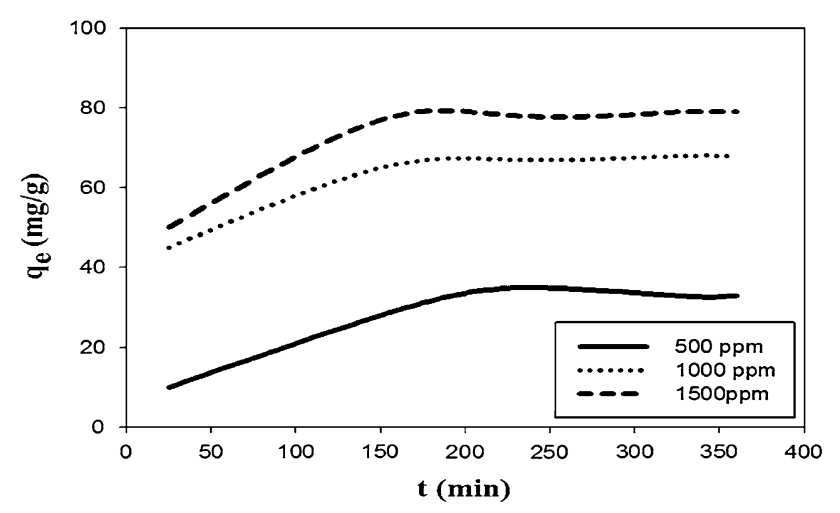

Fig. 5 Effect of different initial concentrations on the sulfur adsorption capacity over the CMK-3 (adsorbent dosage: $20 \mathrm{mg} / \mathrm{L}$, temperature: $25{ }^{\circ} \mathrm{C}$, stirring time: $360 \mathrm{~min}$ )

molecules on the solid and bulk phases. The high adsorption rate at the beginning of the adsorption was because the adsorption of DBT on the external surface of the adsorbent [31]. Adsorption rate depends on various parameters such as stirring rate, physical properties of adsorbent, adsorbent quantity and adsorbate properties. For all initial concentrations (500-1,500 $\mathrm{mg} / \mathrm{L})$, the amount of DBT adsorbed by the OMC increases with time and sometimes; it has continuous improvement outside when DBT is completely adsorbed from the solution. The quantity of DBT adsorbed at the equilibrium time produces the maximum adsorption capacity of the adsorbent under those activating conditions.

\section{Effect of mass of adsorbents}

The effect of the mass of mesoporous carbon in contrast with adsorbent qualities was also studied. The quantities of DBT adsorbed onto OMC are shown in Fig. 6. The results

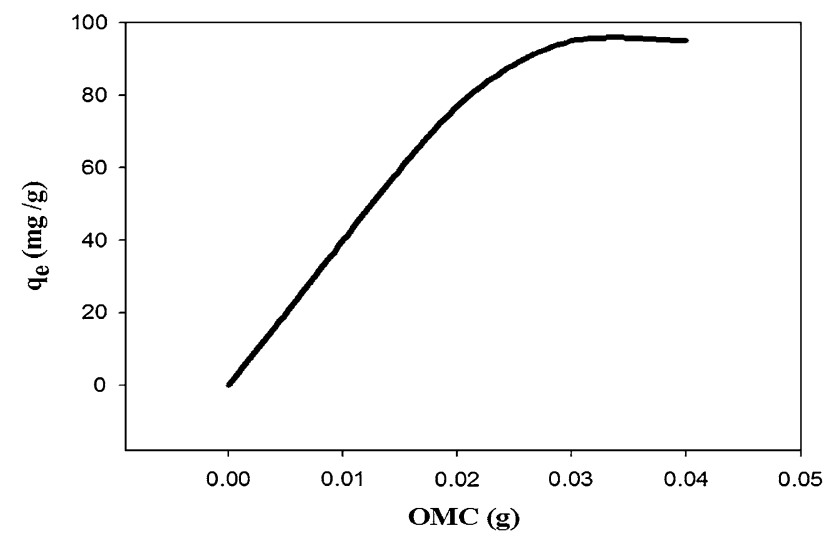

Fig. 6 Effect of mass of adsorbent on the sulfur adsorption capacity over the OMC (DBT: $1,000 \mathrm{mg} / \mathrm{L}$, temperature: $25^{\circ} \mathrm{C}$, stirring time: $180 \mathrm{~min})$ show that the quantity of DBT adsorbed by mesoporous carbon is improved with the increasing amount of the adsorbent.

\section{Effect of temperature}

By increasing the temperature, the adsorption of DBT on OMC is to some extent improved and the adsorption capacity increased only from 50 to $57 \mathrm{mg}(\mathrm{S}) / \mathrm{g}$ adsorbent (Fig. 7).

This demonstrates that the temperature is less important for the desulfurization performance.

\section{Langmuir and Freundlich isotherms}

Adsorption isotherms can state the distribution of DBT molecules between the liquid and solid phases at equilibrium. The Langmuir and Freundlich isotherms are usually used to define the adsorption occurrences at the solid-liquid interface. Langmuir model occurs on concentrated sites with no interaction between adsorbate molecules. Maximum adsorption occurs when the surface is covered by a monolayer of adsorbate [32]. The Langmuir equation demonstrates the amount of DBT adsorbed and its concentration in solution is given in Eq. (3):

$\frac{c_{\mathrm{e}}}{q_{\mathrm{e}}}=\frac{1}{\left(q_{\mathrm{m}} b\right)+\left(1 / q_{\mathrm{m}}\right) c_{\mathrm{e}}}$

where $q_{\mathrm{e}}\left(\mathrm{mg} \mathrm{g}^{-1}\right)$ is the amount adsorbed at equilibrium concentration $C_{\mathrm{e}}\left(\mathrm{mg} \mathrm{L}^{-1}\right), q_{\mathrm{m}}\left(\mathrm{mg} \mathrm{g}^{-1}\right)$ is the Langmuir constant representing maximum monolayer capacity and $b$ is the Langmuir constant related to the energy of adsorption. The Freundlich relation describes multilayer sorption and can be stated as Eq. (4):

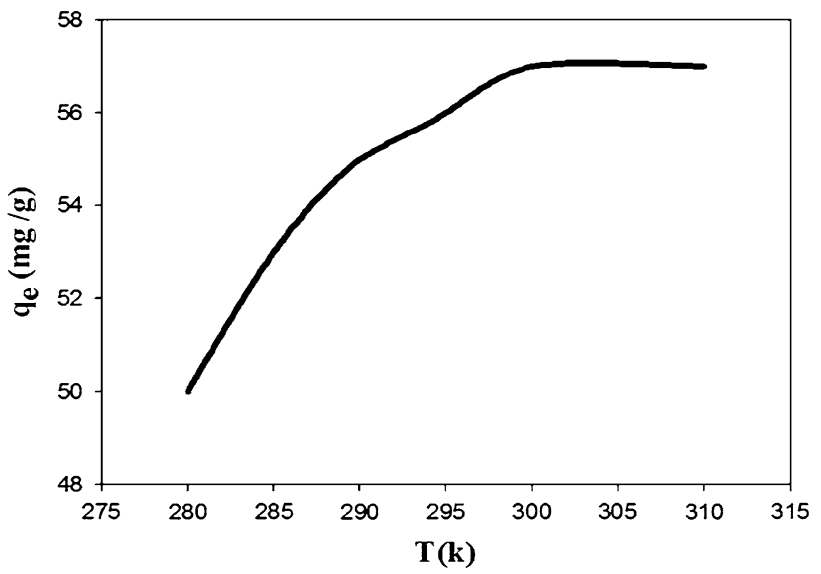

Fig. 7 Effect of temperature on the sulfur adsorption capacity over the OMC (DBT: 1,000 $\mathrm{mg} / \mathrm{L}$, stirring time: $60 \mathrm{~min}$, adsorbent dosage: $20 \mathrm{mg} / \mathrm{L})$ 


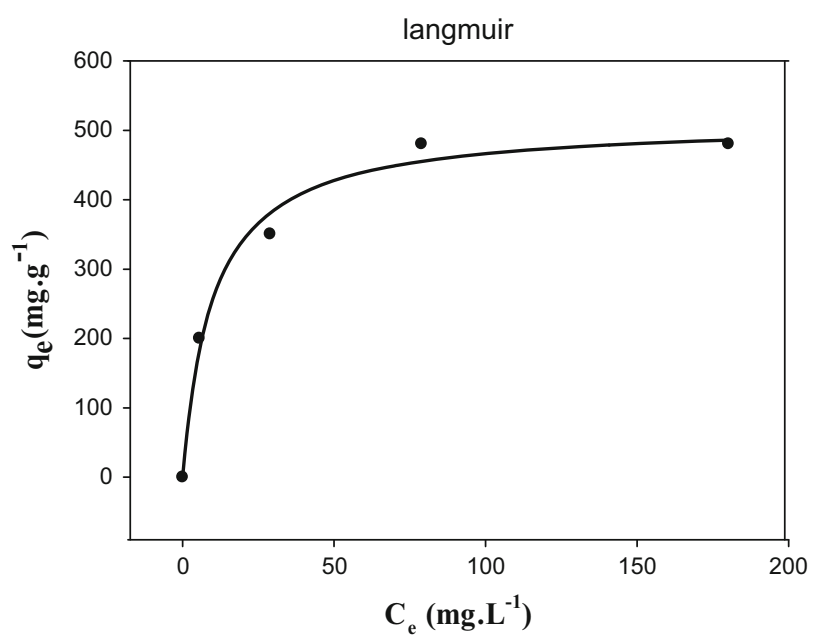

Fig. 8 Langmuir isotherm of dibenzothiophene on OMC

Table 3 Summary of parameters calculated from fitting the results of adsorption isotherm of DBT

\begin{tabular}{|c|c|c|c|c|c|c|}
\hline \multirow{2}{*}{$\begin{array}{l}\text { Temperature } \\
(\mathrm{K})\end{array}$} & \multicolumn{3}{|c|}{ Langmuir } & \multicolumn{3}{|c|}{ Freundlich } \\
\hline & $\begin{array}{l}q_{\mathrm{m}} \\
(\mathrm{mg} / \mathrm{g})\end{array}$ & $\begin{array}{l}b \\
(\mathrm{~L} / \mathrm{mg})\end{array}$ & $R^{2}$ & $\begin{array}{l}k_{\mathrm{f}} \\
(\mathrm{mg} / \mathrm{g})\end{array}$ & $\begin{array}{l}n \\
(\mathrm{~L} / \mathrm{mg})\end{array}$ & $R^{2}$ \\
\hline 298 & 5.135 & 0.1 & 0.9889 & 155.87 & 4.329 & 0.9682 \\
\hline
\end{tabular}

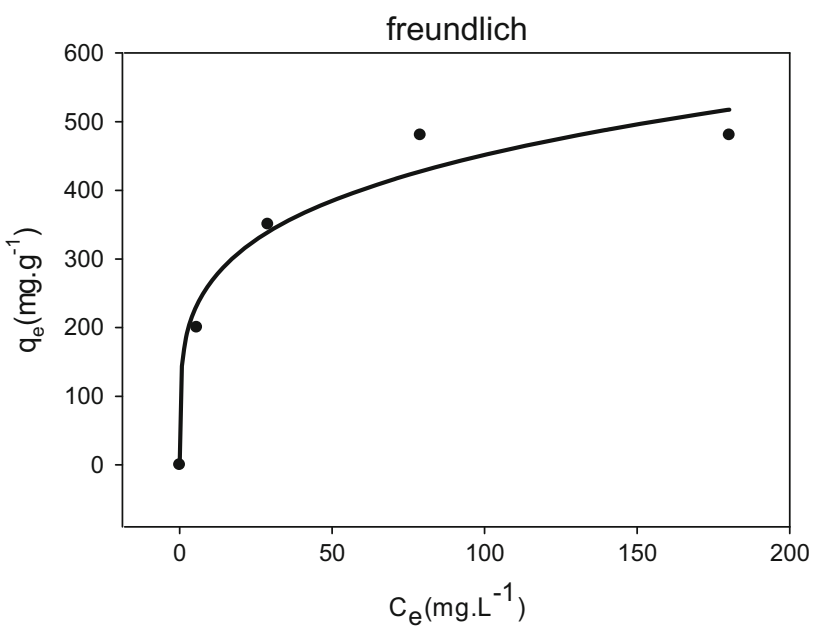

Fig. 9 Freundlich isotherm of dibenzothiophene on OMC

$\ln q_{\mathrm{e}}=\ln k_{\mathrm{f}}+\left(\frac{1}{n}\right) \ln c_{\mathrm{e}}$

where $k_{\mathrm{f}}$ and $n$ are the Freundlich constants related to the adsorption capacity and intensity, respectively. The isotherm data have been drawn using the Langmuir equation and depicted in Fig. 8. The regression constants are recorded in Table 3 . The high value of correlation coefficient indicates good contract between the parameters. The same data are also fitted by the Freundlich equation and are shown in Fig. 9 and Table 3. The value of correlation coefficients shows that the Langmuir isotherm is the most appropriate equation to describe the adsorption equilibrium of DBT on OMC.

\section{Conclusions}

In this work, a novel adsorbent has been successfully synthesized and its adsorption behavior was examined. XRD and $\mathrm{N}_{2}$ adsorption results prove that the OMC using the hard template method is a perfect replica of its template SBA-16. Adsorption of dibenzothiophene (DBT) from fuel solution over numerous porous adsorbents such as CMK-3, SBA-15, and OMC has been studied. It is concluded that different porous materials considerably have different adsorption capacities towards sulfur removal, which depend not only on the textural structures of the porous materials but also on the surface functional groups. It was found that the amount of DBT adsorption on OMC is higher than SBA16. Equilibrium study for both adsorbents has shown experimental results to better fit the Langmuir isotherm. Overall, the results show that $\mathrm{OMC}$ is an efficient and promising adsorbent for separation of DBT from liquid samples.

Acknowledgments This work was supported by the Research Laboratory of Advanced Materials, Chemistry and Chemical Engineering Research Center of Iran.

Open Access This article is distributed under the terms of the Creative Commons Attribution License which permits any use, distribution, and reproduction in any medium, provided the original author(s) and the source are credited.

\section{References}

1. Fallah, R.N., Azizian, S.: Removal of thiophenic compounds from liquid fuel by different modified activated carbon cloths. Fuel Process. Technol. 93, 45-52 (2012)

2. Muzic, M., Sertic-Bionda, K., Gomzi, Z., Podolski, S., Telen, S.: Study of diesel fuel desulfurization by adsorption. Chem. Eng. Res. Des. 88, 487-495 (2010)

3. Ania, C.O., Bands, T.J.: Metal-loaded polystyrene-based activated carbons as dibenzothiophene removal media via reactive adsorption. Carbon 44, 2404-2412 (2006)

4. Houalla, M., Broderick, D.H., Sapre, A.V., Nag, N.K., de Beer, V.H.J., Gates, B.C., Kwart, H.: Hydrodesulfurization of methylsubstituted dibenzothiophenes catalyzed by sulfide $\mathrm{Co}-\mathrm{Mo} / \gamma-$ $\mathrm{Al}_{2} \mathrm{O}_{3}$. J. Catal. 61, 523-527 (1980)

5. Song, C.: An overview of new approaches to deep desulfurization for ultra-clean gasoline, diesel fuel and jet fuel. Catal. Today $\mathbf{8 6}$, 211-263 (2003)

6. Cristol, S., Paul, J.F., Payen, E., Bougeard, D., Hutschka, F., Clémendot, S.: DBT derivatives adsorption over molybdenum sulfide catalysts: a theoretical study. J. Catal. 224, 138-147 (2004) 
7. Ma, X., Sakanishi, K., Isoda, T., Mochida, I.: Hydrodesulfurizationreactivities of narrow-cut fractions in a gas oil. Ind. Eng. Chem. Res. 34, 748-754 (1995)

8. Ma, X., Sakanishi, K., Isoda, T., Mochida, I.: Hydrodesulfurizationreactivities of various sulfur compounds in diesel fuel. Ind. Eng. Chem. Res. 33, 218-222 (1994)

9. Song, C.: Fuel processing for low-temperature and high-temperature fuel cells: challenges, and opportunities for sustainable development in the 21st century. Catal. Today 77, 17 (2002)

10. Awuala, M.R., Yaitaa, T., Taguchib, T., Shiwakua, H., Suzukia, S., Okamoto, Y.: Selective cesium removal from radioactive liquid waste by crown ether immobilized new class conjugate adsorbent. J. Hazard. Mater. 278, 227-235 (2014)

11. Blanco-Brieva, G., Campos-Martin, J.M., Al-Zahrani, S.M., Fierro, J.L.G.: Thermal regeneration of the metal organic frameworks used in the adsorption of refractory organosulfur compounds from liquid fuels. Fuel 150, 459-465 (2013)

12. Delitala, C., Cadoni, E., Delpiano, D., Meloni, D.: Liquid-phase thiophene adsorption on MCM-22 zeolite. Microporous Mesoporous Mater. 110, 215 (2008)

13. Tang, K., Song, L.-J., Duan, L.-H., Li, X.-Q., Gui, J.-Z., Sun, Z.L.: Deep desulfurization by selective adsorption on a heteroatoms zeolite prepared by secondary synthesis. Fuel Process. Technol. 89, 1-6 (2008)

14. Wang, L., Sun, Z., Ding, Y., Chen, Y., Li, Q., Xu, M., Li, H., Song, L.: A theoretical study of thiophenic compounds adsorption on cation-exchanged Y zeolites. Appl. Surf. Sci. 257, 7539-7544 (2011)

15. Tang, K., Hong, X., Zhao, Y., Wang, Y.: Adsorption desulfurization on a nanocrystalline $\mathrm{NaY}$ zeolite synthesized using carbon nanotube templated growth. Pet. Sci. Technol. 29, 779-787 (2011)

16. Che, S., Lund, K., Tatsumi, T., Iijima, S., Joo, S.H., Ryoo, R., Terasaki, O.: Direct observation of 3D mesoporous structure by scanning electron microscopy (SEM): SBA-15 silica and CMK-5 carbon. Angew. Chem. Int. Ed. 42, 2182-2185 (2003)

17. Awual, M.R., Suzuki, S., Taguchi, T., Shiwaku, H., Okamoto, Y., Yaita, T.: Radioactive cesium removal from nuclear wastewater by novel inorganic and conjugate adsorbents. Chem. Eng. J. 242 , 127-135 (2014)

18. Kim, T.-W., Ryoo, R., Gierszal, R.P., Jaroniec, M., Solovyov, L.A., Sakamoto, Y., Terasaki, O.: Characterization of mesoporous carbons synthesized with SBA-16 silica template. J. Mater. Chem. 15, 1560-1571 (2005)

19. Awual, M.R., Kobayashi, T., Shiwaku, H., Miyazaki, Y., Motokawa, R., Suzuki, S., Okamoto, Y., Yaita, T.: Evaluation of lanthanide sorption and their coordination mechanism by EXAFS measurement using novel hybrid adsorbent. Chem. Eng. J. 225, 558-566 (2013)
20. Han, S., Kim, S., Lim, H., Choi, W., Park, H., Yoon, J., Hyeon, T.: New nanoporous carbon materials with high adsorption capacity and rapid adsorption kinetics for removing humic acids. Microporous Mesoporous Mater. 58, 131-135 (2003)

21. Ohkubo, T., Miyawaki, J., Kaneko, K., Ryoo, R., Seaton, N.A.: Adsorption properties of templated mesoporous carbon (CMK-1) for nitrogen and supercritical methane experiment and GCMC simulation. J. Phys. Chem. B 106, 6523-6528 (2002)

22. Joo, S.H., Choi, S.J., Oh, I., Kwak, J., Liu, Z., Terasaki, O., Ryoo, R.: Ordered nanoporous arrays of carbon supporting high dispersions of platinum nanoparticles. Nature 412, 169-172 (2001)

23. Jun, S., Joo, S.H., Ryoo, R., Kruk, M., Jaroniec, M., Liu, Z., Ohsuna, T., Terasaki, O.: Synthesis of new nanoporous carbon with hexagonally ordered mesostructure. J. Am. Chem. Soc. 122, 10712-10713 (2000)

24. Khazaeli, N.S., Rabani, M., Panahi, H.A.: A new functionalized resin and its application in flame atomic absorption spectrophotometric determination of trace amounts of heavy metal ions after solid phase extraction in water samples. Microchem. J. 106, 147 (2013)

25. Zhao, D., Feng, J., Huo, Q., Melosh, N., Fredrickson, G.H., Chmelka, B.F., Stucky, G.D.: Triblock copolymer syntheses of mesoporous silica with periodic 50 to 300 angstrom pores. Science 279, 548-552 (1998)

26. Zhao, D., Huo, Q., Feng, J., Chmelka, B.F., Stucky, G.D.: Nonionic triblock and star diblock copolymer and oligomeric surfactant syntheses of highly ordered, hydrothermally stable, mesoporous silica structures. J. Am. Chem. Soc. 120, 6024-6036 (1998)

27. Guo, Z., Zhu, G., Gao, B., Zhang, D., Tian, G., Chen, Y., Zhang, W., Qiu, S.: Adsorption of vitamin B12 on ordered mesoporous carbons coated with PMMA. Carbon 43, 2344-2351 (2005)

28. Anbia, M., Parvin, Z.: Desulfurization of fuels by means of a nanoporous carbon adsorbent. Chem. Eng. Res. Des. 89, 641-647 (2011)

29. FarzinNejad, N., Shams, E., Amini, M.K., Bennett, G.C.: Synthesis of magnetic mesoporous carbon and its application for adsorption of dibenzothiophene. Fuel Process. Technol. 106, 376-384 (2013)

30. Palomino, J.M., Tran, D.T., Hauser, J.L., Dongc, H., Oliver, S.R.J.: Mesoporous silica nanoparticles for high capacity adsorptive desulfurization. J. Mater. Chem. A 2, 14890-14895 (2014)

31. Haji, S., Erkey, C.: Removal of dibenzothiophene from model diesel by adsorption on carbon aerogels for fuel cell applications. Ind. Eng. Chem. Res. 42, 6933 (2003)

32. SunaErses, A., Fazal, M.A., Onay, T.T., Craig, W.H.: Determination of solid waste sorption capacity for selected heavy metals in landfills. J. Hazard. Mater. 121, 223-232 (2005) 